Lloyd et al. recently found that income growth over the 1991 to 1996 period was roughly twice as rapid in the capital cities as in most other areas of Australia. ${ }^{2}$ The proportion of low income households has been increasing somewhat more rapidly outside the cities.

In Figure 2, all Australians have been ranked by the equivalent gross household income of the local government area in which they live (using the OECD equivalence scale). The bottom decile thus consists of the 10 per cent of Australians who lived in the poorest local government areas. The results suggest that the 10 per cent of Australians living in the most affluent local government areas gained over the 10 years to 1996, with their share of the total income pie increasing by 1.26 percentage points to 14.96 per cent. Overall, the 30 per cent of Australians living in the top three deciles of local government areas increased their share of the total pie. In contrast, the 70 per cent of Australians living in middle and lower income local government areas lost ground, seeing their share of the total income pie shrinking from 63.5 per cent to 61.91 per cent. There is thus some evidence that already rich neighbourhoods are becoming even richer, while poorer neighbourhoods are becoming even poorer.

\section{CONCLUSION}

There has been little change in national overall inequality during this period. But this lack of overall change at the national level disguises two major trends: better outcomes for the poor and the rich than for middle Australia; and an apparent increase in spatial income inequality (that is, inequality of income by geographical regions).

\section{REFERENCES}

1. Harding A. The Suffering Middle: Trends in Income Inequality in Australia 1982 to 1993-94. Australian Economic Review December 1997; 30 (4).

2. Lloyd R, Harding A and Hellwig O. Regional Divide? A Study of Incomes in Regional Australia: Discussion Paper No. 51. Canberra: National Centre for Social and Economic Modelling, September 2000; 5. Downloadable from www.natsem.canberra.edu.au.

\title{
PROMOTION, PREVENTION AND EARLY INTERVENTION IN MENTAL HEALTH: TWO NEW NATIONAL DOCUMENTS
}

\author{
Kym Scanlon, Beverley Raphael and Kathy Paterson \\ Centre for Mental Health \\ NSW Department of Health
}

Mental health has been identified as a key priority area by NSW Health and also nationally. Recent documents have highlighted the increasing burden imposed by mental health problems and disorders in our society. Depression alone has been predicted as one of the greatest problems internationally by the year $2020 .{ }^{1}$ Promotion, prevention and early intervention for mental health has been identified as important to progress, in order to diminish this burden. There is growing evidence that effective promotion, prevention and early intervention initiatives can reduce the prevalence of mental health problems, and lessen the severity and duration of mental illness. ${ }^{2,3,4}$

The National Action Plan for Promotion, Prevention and Early Intervention for Mental Health 2000, 5 and an accompanying Promotion, Prevention and Early Intervention for Mental Health 2000: A Monograph, ${ }^{6}$ were released in late 2000 . These two documents have been developed by the National Promotion and Prevention Working Party, which has representation from the National Mental Health Working Group and the National Public Health Partnership.

Together these documents provide a strategic framework and a plan for action to address promotion, prevention and early intervention priorities and mental health outcomes across Australia. The monograph provides the theoretical and conceptual framework and background information for the action plan.

To support the implementation of the National Action Plan, a New South Wales Promotion, Prevention and Early Intervention Steering Committee has been appointed. Consultation forums to guide implementation are occurring in the area health services across NSW, with 600 people participating in these to date.

Copies of Action Plan 2000 (ISBN 0642 447241) and the Monograph (ISBN 0642 44725X) are available from the Better Health Centre, telephone: (02) 9816 0452; fax: (02) 9816 0492. Feedback on the documents can be provided through a form enclosed at the back of these documents. 


\section{REFERENCES}

1. Murray CJL and Lopez AD. The global burden of disease: A comprehensive assessment of mortality and disability, injuries and risk factors in 1990 and projected to 2020. Cambridge, MA: World Health Organization, 1996.

2. International Union for Health Promotion and Education. The Evidence of Health Promotion Effectiveness: Shaping Public Health in a New Europe. A Report for the European Commission by the International Union for Health Promotion and Education. Luxembourg: International Union for Health Promotion and Education, 1999.

3. Mrazek PJ and Haggerty RJ. Reducing risks for mental disorders: Frontiers for preventive intervention research. Washington DC: National Academy Press, 1994.
4. Durlak JA and Wells AM. Primary prevention mental health programs for children and adolescents: A meta-analytic review. Am J Community Psychol 1997; 25(2): 115-152.

5. Commonwealth Department of Health and Aged Care. National Action Plan for Promotion, Prevention and Early Intervention for Mental Health 2000. Canberra: Commonwealth Department of Health and Aged Care, 2000.

6. Commonwealth Department of Health and Aged Care. Promotion, Prevention and Early Intervention for Mental Health 2000: A Monograph. Commonwealth Department of Health and Aged Care, 2000.

\section{GETTING IN EARLY: A FRAMEWORK FOR EARLY INTERVENTION AND PREVENTION IN MENTAL HEALTH FOR YOUNG PEOPLE IN NEW SOUTH WALES}

\author{
Kathy Paterson, Judy Jones, Bernadette Dagg, Kym \\ Scanlon and Beverley Raphael \\ Centre for Mental Health \\ NSW Department of Health
}

Improving the mental health of young people is a priority of the NSW Government. A substantial number of adolescents and young adults have significant mental health problems. Up to 24 per cent of adolescents experience depression by the time they are 18 years old, and young people aged 15-24 years are the group most frequently affected by a first episode of psychosis. ${ }^{1}$ These mental health disorders have serious consequences for young people and their families including:

- an increased risk of suicide

- an increased risk of hazardous substance use

- disruption to psychological, educational and social development

- strain on relationships.

Mental health problems in young people have been poorly recognised, identified and managed, and there has often been a considerable delay in young people receiving appropriate care. Increasing evidence shows that preventing and intervening early for young people with mental health problems can dramatically improve their immediate and long term health outcomes. ${ }^{1,2}$

Programs and initiatives for depression and first onset psychosis have been established in area health services across NSW. Getting in Early-A Framework for Early Intervention and Prevention in Mental Health for Young People in NSW is a framework for improving and supporting these initiatives.
Five broad strategies are outlined for mental health promotion, prevention and early intervention in young people:

- developing and coordinating comprehensive programs and services;

- engaging young people and their families and providing comprehensive assessment and management;

- developing and implementing prevention programs;

- educating the community, particularly on depression and related disorders and first onset psychosis in young people;

- monitoring quality and effectiveness.

Getting in Early provides an innovative framework for mental health service delivery for young people. Getting in Early also presents an opportunity to emphasise and maximise mental health services working collaboratively with other agencies towards better mental health for young people in NSW.

Copies of Getting in Early (Publication No. CMH00014) are available from the Better Health Centre, telephone: (02) 9816 0452; fax: (02) 98160492.

\section{REFERENCES}

1. National Health and Medical Research Council. Depression in young people: Clinical practice guidelines. Canberra, ACT: Australian Government Publishing Service, 1997.

2. Loebel AD, Lieberman JA, Alvir JM, Mayerhoff DI, Geisler SH, and Szymanski SR. Duration of psychosis and outcome in first-episode schizophrenia. Am J Psychiatry 1992; 149: 1183-1188. 